\title{
Immersive Learning Experience pada Pembelajaran Daring dengan Penggunaan Virtual Reality
}

\author{
Mangapul Siahaan*1, Katherine Oktaviani ${ }^{2}$, Julia $^{3}$ \\ ${ }^{1,2}$ Universitas Internasional Batam, Prodi Sistem Informasi; \\ Jln Gajah Mada, Baloi Permai, Sekupang, telp. 07787437111 \\ e-mail: *1mangapul.siahaan@uib.ac.id, ${ }^{2}$ 1931153.katherine@uib.edu, ${ }^{3}$ 1931154.julia@uib.edu
}

\begin{abstract}
Abstrak
Penelitian ini dilakukan untuk menganalisa dan menggagas model pembelajaran yang berpotensi meningkatkan efektivitas pembelajaran daring dengan cara meningkatkan student engagement dan motivasi belajar melalui penerapan Virtual Reality dan Gamification in Learning. Analisa dilakukan dengan metode meta-analisis jurnal dimana tim penulis melakukan penelusuran terhadap berbagai sumber artikel dan jurnal untuk menggagas suatu model pembelajaran menarik untuk diterapkan dalam pembelajaran jarak jauh. Melalui penelitian, ditemukan bahwa model pembelajaran daring yang saat ini digunakan belum efektif serta berisiko menurunkan student engagement dan motivasi belajar. Dengan keunikannya dalam menjaring student engagement, teknologi Virtual Reality dan gamification in learning dapat dipertimbangkan sebagai pelengkap, media, dan metode untuk pembelajaran daring.
\end{abstract}

Kata kunci-Pembelajaran daring, Virtual reality, Gamification in learning, COVID-19

\begin{abstract}
This research is done to analyze and conceptualize a learning model which has potentials to increase online learning effectivity by means of increasing student engagement and learning motivation via implementation of virtual reality technology and gamification in learning. Analysis is done by methods of meta-analysis of journals where researcher's team did extensive search towards various sources of articles and journals to conceptualize an interesting learning model to be implemented in long distance learning/online learning. According to research done, it is summarized that the current learning model is not yet effective and have potential risks of inhibiting student engagement and learning motivation. With its uniqueness in garnering engagement, virtual reality technology and gamification in learning could be reconsidered as a complement, media, and methods to online learning
\end{abstract}

Keywords-Online learning, virtual reality, gamification in learning, COVID-19

\section{PENDAHULUAN}

Virtual Reality adalah teknologi level atas yang berada pada komputer yang meliputi simulasi secara real-time dan interaksi pada berbagai kanal sensori. Sensoring dapat berupa visual, suara, sentuhan, dan bila memungkinkan pembau dan perasa [1]. VR dibuat ataupun disimulasikan oleh komputer yang biasanya diperlihatkan melalui head mounting screen, dengan alat yang diletakkan di kepala dan dipakai seperti kacamata untuk melihat proyeksi dari layar yang akan menunjukkan hasil simulasi dari komputer.

Hal penting dari VR selain dapat melihat dunia yang disimulasikan oleh komputer, adalah interaksi terhadap dunia tersebut. Interaksi pada VR ini bisa melalui suatu controller yang berada pada tiap tangan dan memiliki tombol untuk menggerak tiap jari karakter yang berada pada VR biasanya karakter manusia. Selain dari itu tangan yang berada di VR juga bisa bergerak jika tangan bergerak secara realtime.

Selain dari segi interaktivitas dari VR sensasi yang lainnya yang bisa diimplementasikan pada VR adalah sensasi memegang objek bisa dilakukan dengan mengirim listrik pada controller pada bagian tertentu pada tangan sehingga dapat menstimulasi sensasi memegang sesuatu. Selain itu headset bisa dimodifikasi untuk mengeluarkan bau tertentu tergantung pada tempat ataupun bau suatu barang. Hal ini sangat membantu dalam membuat pengalaman VR lebih imersif.

Dengan hal seperti teknologi VR bukan hanya membuat seorang berada pada dunia yang disimulasikan saja tetapi bisa sangat membantu dalam membuat subjek hadir pada dunia tersebut dan membuat subjek tersebut imersif terhadap dunia sehingga percaya bahwa pengguna benar-benar berada 
pada dunia tersebut, dan ditambahkan dengan interaktivitas VR tersebut dapat membuat pengguna tetap terpikat sehingga tidak akan keluar terlalu cepat dalam kebosanan.

Sehingga VR ini tepat guna sebagai sarana hiburan dan segi aplikatif lainnya, salah satunya adalah pada dunia pendidikan yang dengan beberapa aspek di atas, dapat membantu efektivitas dan keberhasilan pembelajaran. Pendidikan merupakan esensi penting dalam hidup manusia. Budi pekerti, moral dan tingkah laku tidak terlepas dari pendidikan, baik formal maupun non-formal. Dalam tingkatan formal, Indonesia memiliki program 12 tahun wajib belajar serta dilanjutkan dengan pendidikan tinggi. Dalam situasi darurat saat ini, yaitu pandemi COVID, masyarakat diimbau agar menetap di rumah dan mengurangi aktivitas di luar. Dengan begitu, kegiatan sosialisasi apapun efektif terhentikan, termasuk kegiatan pendidikan. Satu-satunya solusi yang dapat dilakukan agar anak-anak bangsa dapat menamatkan pendidikan adalah dengan pembelajaran daring atau pendidikan jarak jauh.

Namun pendidikan jarak jauh atau PJJ membuahkan suatu masalah baru yaitu berkurangnya engagement dan interaksi dalam kelas, menghasilkan proses pembelajaran yang tidak efektif dan efisien. Oleh karena itu, tim penulis melakukan penelitian penerapan Virtual Reality dalam pembelajaran yang saat ini dilakukan secara daring serta perancangan modul Virtual Reality dalam sistem pembelajaran daring saat ini

\section{METODE PENELITIAN}

Penelitian ini dilakukan dengan metode meta-analisis jurnal. Meta-analisis diterapkan dengan menelusuri, meringkas, analisa dan review hasil penelitian yang sebelumnya pernah dilakukan. [2] Hasil penelitian yang sudah pernah dilakukan didapat melalui jurnal-jurnal penelitian yang dapat dicari melalui scholar.google.com. Lebih spesifiknya, meta-analisis jurnal bersifat kualitatif, yaitu dengan mengambil data deskriptif dan bukan data kuantitatif dari hasil penelitian sebelumnya. Jurnal-jurnal yang digunakan dalam meta-analisis ini ditelusuri menggunakan kata kunci "virtual reality", "pembelajaran daring", "pembelajaran luring", "gamification in learning", dan kata kunci relevan lainnya. Jurnal-jurnal yang digunakan bervariasi dari yang berbahasa Indonesia hingga berbahasa Inggris dari paling lama 5 (lima) tahun terakhir untuk data-data yang menjadi basis penelitian ini.

Hasil penelitian dari jurnal yang ada digunakan sebagai dasar untuk penelitian yang dilakukan ini. Output yang diharapkan yaitu konsepsi modul-modul beserta model pembelajaran yang memungkinkan untuk diterapkan menggunakan Virtual Reality dalam kondisi pembelajaran daring seperti yang saat ini dilakukan

\subsection{Teknologi Virtual Reality}

Teknologi Virtual Reality telah mengalami perkembangan pesat mulai dari visi Ivan Sutherland berupa Ultimate Display yang dikemukakannya dalam sebuah jurnal pada tahun 1965 hingga teknologi Virtual Reality seperti yang kita jumpai pada Google VR. Menurut Ivan Sutherland (1965), jika tujuan suatu display adalah sebagai jendela untuk dunia yang terletak dalam suatu memori komputer, maka display harus memenuhi kebutuhan berbagai indera yang ada. Oleh karena itu, ultimate display haruslah menjadi suatu ruangan/kamar yang dapat dikendalikan oleh komputer. [3]. Istilah Virtual Reality sendiri digagas oleh Jaron Lanier pada tahun 1989 yang akhirnya mendorong berbagai penelitian dan usahausaha untuk merancang suatu mesin guna mencapai virtual reality tersebut.

Kemudian pada tahun 2012, digagas suatu proyek bernama Oculus Rift yang mencari pendanaan untuk penelitiannya. Hal ini kembali mendorong gelombang kedua VR, yang mendorong animo penelitian hingga saat ini. [4] Beberapa contoh produk teknologi Virtual Reality saat ini adalah Samsung Galaxy Gear VR dan Google Cardboard. Samsung Galaxy Gear VR dirilis pada tahun 2016 dan memiliki beberapa spesifikasi yaitu gear berbobot 345 gram, memiliki accelerometer, gyro sensor dan proximity sensor, yang menunjang kinerja Gear ini [5]. Namun sayangnya, Samsung Galaxy Gear VR sudah tidak diproduksi lagi. Produk kedua adalah Google Cardboard yang memiliki keunikan berupa viewer dari cardboard/karton dan virtual experience yang dapat direkayasa sendiri melalui Cardboard SDK yang tersedia. Sesuai dengan motto-nya, "Experience virtual reality in a simple, fun and affordable way", Google Cardboard mengarah kepada virtual reality yang sederhana dan terjangkau. [6]

Melihat animo masyarakat dan perkembangan Virtual Reality yang terus meningkat, Virtual Reality memiliki potensi yang cukup tinggi dalam penggunaannya dalam berbagai aspek di masyarakat

Berikut ilustrasi alat dan penggunaan teknologi Virtual Reality. 


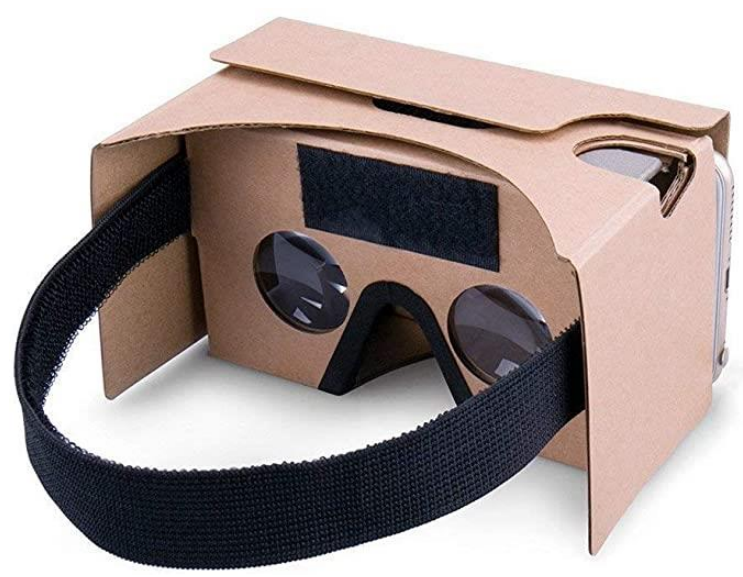

Gambar 1 Ilustrasi Google Cardboard merupakan teknologi Virtual Reality yang ada saat ini Sumber: amazon.co.uk

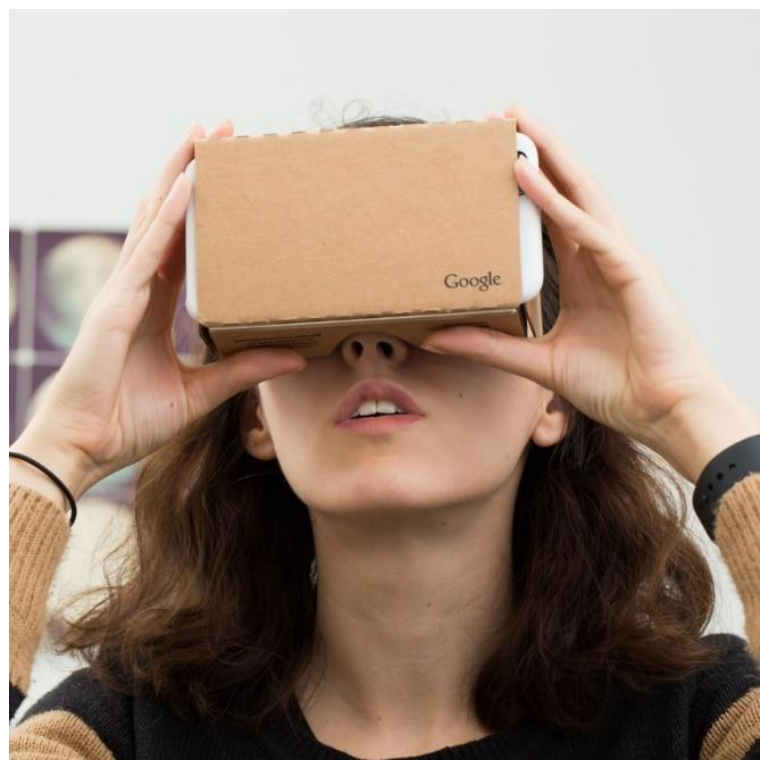

Gambar 2 Pemakaian Google Cardboard, yang juga termasuk penggunaan head mounting screen. Sumber: theverge.com

\subsection{Penerapan Pembelajaran Daring}

Pembelajaran pada dasarnya adalah suatu proses dimana peserta didik dan pendidik berinteraksi baik secara langsung (tatap muka) maupun tidak langsung (dijembatani media aplikasi). Di tengah pandemi COVID-19 kegiatan belajar mengajar (KBM) diarahkan untuk penggunaan model pembelajaran daring [7].

Blended learning adalah strategi pembelajaran melalui pemanfaatan teknologi internet (eLearning) bersama dengan kelas tatap muka. Metode pembelajaran ini bertujuan untuk meningkatkan hasil akademik peserta didik, pengajaran oleh pendidik, pembelajaran oleh peserta didik, dan respon peserta didik dalam penerapan strategi pembelajaran Blended learning [8].

Pembelajaran daring selama ini diterapkan melalui bantuan media seperti e-classroom, live chat, zoom, atau WhatsApp Group [9]. Namun perlu disadari bahwa penerapan seperti ini cenderung terasa intangible, sehingga tenaga pengajar harus mampu menarik student engagement dengan cara yang tentunya berbeda dan unik seluruhnya dibandingkan ketika pembelajaran luring. Selain tenaga pengajar, peserta didik harus memiliki motivasi belajar yang kuat ketika berpartisipasi dalam pembelajaran daring ini. Singkatnya, seluruh pihak harus memiliki tingkat kepercayaan dan kerjasama yang kuat supaya pembelajaran daring dapat berjalan dengan lancar.

Berdasarkan penelitian yang dilakukan oleh Utami dan Cahyono (2020) pada siswa-siswi SMA/MA terkait analisis kesulitan belajar Matematika, didapati bahwa rata-rata pencapaian indicator kesulitan belajar siswa terhadap pelajaran Matematika melalui sistem pendidikan e-learning adalah sebesar $75 \%$, dengan indikator yang paling tinggi akibat kendala teknis sinyal dan ketidak mampuan 
dalam belajar online sebesar 77\%. Melalui penelitian, diperoleh kesimpulan bahwa kerumitan e-learning dan kendala sarana-prasarana menghambat siswa-siswi untuk belajar secara maksimal. [10]. Berhubungan dengan respon peserta didik dalam pelaksanaan pembelajaran daring, ditemukan pula melalui penelitian oleh Sadikin dan Hamidah (2020) pada pembelajaran daring di Prodi Pendidikan Biologi FKIP Universitas Jambi, bahwa respon mahasiswa cukup positif dengan adanya fleksibilitas ruang dan waktu serta rasa nyaman mahasiswa untuk mengemukakan pendapat. Di sisi lain, akses internet, kuota dan kecanduan gawai membuka masalah baru. [11]

Adapun persepsi mahasiswa Program Studi Teknologi Pendidikan Universitas Baturaja melalui penelitian yang dilakukan oleh Ningsih (2020) didapatkan bahwa mayoritas mahasiswa memilih untuk belajar luring dikarenakan beberapa kendala seperti kuota internet, penjelasan materi yang kurang maksimal dan interaksi pembelajaran yang terbatas. Namun mahasiswa tetap merasakan dampak positifnya. [12]

\subsection{Aspek Pembelajaran Daring}

Salah satu aspek pembelajaran daring yaitu memungkinkannya dilakukan secara asynchronous ataupun synchronous. Asynchronous terjadi dimana pembelajaran dilakukan pada waktu yang berbedabeda sesuai dengan waktu yang diinginkan peserta didik. Jika peserta didik mau, pembelajaran bisa dilakukan sesuai dengan waktu yang diinginkan. Contoh penerapan asynchronous adalah pembelajaran materi melalui LMS (Learning Management System). Synchronous terjadi bila pembelajaran dilakukan pada waktu yang telah ditentukan sebelumnya secara real-time. Contohnya adalah video conference [13]. Aspek lainnya adalah kebebasan dalam mempelajari dan memilih materi, dibandingkan dengan situasi kelas yang pesertanya hanya dapat melakukan kegiatan belajar pada waktu tertentu dan tempat tertentu. Melalui pembelajaran daring, peserta didik dapat melakukannya secara bebas kapanpun sehingga kegiatan belajar mengajar mampu menyesuaikan dengan jadwal peserta didik. [14]

Selain itu, kemandirian belajar dan keaktifan peserta didik menjadi aspek yang harus diperhatikan dalam pembelajaran daring. Semakin dewasa, mandiri, dan aktif peserta didik dalam mengikuti pembelajaran, maka pembelajaran daring akan lebih berguna dan lebih efektif [9].

\subsection{Student Engagement}

Student engagement mengukur kesediaan peserta didik untuk meluangkan waktu, usaha, dan partisipasi untuk mencapai hasil yang diinginkan yaitu prestasi akademik [13]. Student engagement merupakan salah satu aspek yang cukup sulit diperoleh, baik dalam pembelajaran luring maupun daring. Student engagement yang positif menghasilkan prestasi akademik yang positif pula. Hal ini dibuktikan, melalui penelitian oleh Gunuc pada tahun 2014 dan juga Sa'adah beserta Ariati pada tahun 2018, memiliki korelasi positif antara student engagement dengan prestasi akademik. [13]

\subsection{Immersive Learning Experience}

Pembelajaran imersif merupakan hal penting sebagai upaya yang dapat membuat siswa masuk ke dalam suasana permainan dan mendapatkan pengalaman lebih dari permintaan tersebut [15]. Pembelajaran experiential learning mempengaruhi kemampuan berpikir kritis, sesuai dengan penelitian yang dilakukan oleh Sari (2013), yaitu model pembelajaran outdoor experiential learning bisa menaikkan keterampilan proses \& akal budi kritis murid. Outdoor experiential learning menaikkan keterampilan \& akal budi kritis murid terutama dalam materi sekolah. Melalui aktivitas pembelajaran yg berbasis pengalaman, siswa yg melakukan pengamatan pada lingkungan ternyata mempunyai keterampilan proses belajar \& akal budi kritis yg lebih tinggi dibanding aktivitas pembelajaran teoritis[16]. Oleh sebab itu, Immersive Learning experience seharusnya menjadi tujuan utama dalam pembelajaran daring untuk mencapai target dari suatu pembelajaran itu sendiri.

\subsection{Gamification in Learning}

Gamification adalah pendekatan penggunaan elemen-elemen di dalam game atau video game dengan tujuan memotivasi para siswa dalam proses pembelajaran. Media ini dapat digunakan untuk menangkap hal-hal yang menarik minat peserta didik dan menginspirasinya untuk terus berpartisipasi dalam pembelajaran. Proses pembelajaran menggunakan gamifikasi memberikan alternatif sehingga proses belajar menjadi lebih menarik, menyenangkan dan efektif. Meskipun digunakan mekanika permainan, penerapan gamifikasi tidak selalu berujung membuat games/permainan, tetapi bagaimana membuat pembelajaran lebih menyenangkan, membangun engagement tanpa disadari peserta didik [17].

Beberapa contoh penerapan gamifikasi yang telah berhasil meningkatkan ketertarikan pengguna, 
yaitu Angry Bird (untuk pelajaran fisika), Pokemon (untuk pelajaran bahasa, artscience, map), Minecraft (untuk pelajaran arsitektur). Elemen yang ada pada suatu games atau yang disebut mekanik games dan dinamika games selalu dirancang oleh desain games agar membuat orang selalu tertantang untuk terus menerus memainkannya dan mencapai pencapaian paling tinggi di Games. Dalam pendidikan, gamification memungkinkan mahasiswa untuk menerima umpan balik langsung mengenai perkembangan mereka di dalam kelas dan penghargaan terhadap tugas yang diselesaikan. Sebuah studi mengenai efektivitas gamification terhadap engagement pengguna dan hasil dari studi tersebut menunjukkan bahwa gamification memiliki efek positif terhadap engagement pengguna yakni pelajar. Mereka yang level engagement-nya tinggi, terindikasi memiliki lebih banyak lencana-lencana dari para gurunya dan begitu pula sebaliknya. Selain prinsip umum dalam strategi pembelajaran, terdapat juga prinsip khusus yang terdiri dari interaktif, inspiratif, menyenangkan, menantang, dan memberi motivasi[17].

\section{HASIL DAN PEMBAHASAN}

\subsection{Pelaksanaan Pembelajaran Daring Saat Ini}

Pembelajaran jarak jauh bukanlah hal yang asing dalam jenjang pendidikan tinggi. Namun bagi pendidikan dasar dan menengah, pembelajaran jarak jauh atau sekarang ini disebut pembelajaran daring (dalam jaringan) merupakan sesuatu yang tidak lazim dan akibatnya, mendapatkan respon yang bervariasi. Pembelajaran daring bagi pendidikan dasar hingga pendidikan tinggi saat ini dilakukan hampir secara totaliter akibat merebaknya pandemic COVID-19 secara global. Memenuhi tuntutan kesehatan, Indonesia juga menerapkan pembelajaran daring bagi peserta didik. Hingga saat ini, pembelajaran daring yang telah diterapkan sudah berjalan hampir satu tahun. Pembelajaran daring pada umumnya dilakukan melalui media aplikasi seperti Microsoft Teams, Google Classroom, Zoom, Webex dan lain sebagainya. Pembelajaran memilki variasi dalam pembelajaran asynchronous (melalui learning management system seperti Google Classroom dan Moodle) dan synchronous (melalui video conference tools seperti Microsoft Teams, Google Meet, dan Zoom). Penentuannya diserahkan kepada otonomi masing-masing perangkat pendidikan.

Pemebelajaran seperti ini tentunya membutuhkan sarana dan prasarana yang mumpuni. Pertama dibutuhkan ketersediaan perangkat untuk mengakses aplikasi pembelajaran (seperti handphone, laptop atau komputer). Kedua dibutuhkan sarana jaringan internet. Seperti yang sebelumnya telah dikemukakan, cukup banyak respon positif yang didapatkan dengan diterapkannya pembelajaran daring, sperti rasa nyaman peserta didik dalam mengikuti pembelajaran, kemelekan teknologi yang dirasakan, dan fleksibilitas waktu dan ruang. Namun di sisi lain, peserta didik tetap merasakan keterbatasan, salah satunya keterbatasan dalam interaksi dan penyampaian materi oleh dosen.

Dari itu, pembelajaran daring dapat dianggap memiliki pelaksanaan yang mencukupi. Namun tentunya dapat ditingkatkan kembali, salah satunya pada interaktivitas dan efektivitas dalam penyampaian materi yang dilakukan tenaga pengajar.

\subsection{Penerapan Virtual Reality dan Gamification in Learning pada Pembelajaran Daring (dalam jaringan)}

Gamifikasi, yaitu penerapan unsur game design dalam dunia nyata untuk kegunaan yang bukan berorientasi game, bertujuan untuk meningkatkan ketertarikan user pada aktivitas tertentu [18]. Dalam penggunaannya bersama teknologi Virtual Reality, dengan tujuan meningkatkan motivasi belajar dan ketertarikan siswa dalam pembelajaran, gamification in learning merupakan model pembelajaran yang diterapkan melalui media Virtual Reality. Dikarenakan pandemi ini, maka pembelajaran dilakukan secara daring, dengan arti pembelajaran sudah tidak bisa diterapkan menggunakan metode konvensional. Tidak menutup kemungkinan bahwa Virtual Reality dapat diterapkan untuk meningkatkan efektivitas pembelajaran daring ataupun luring (offline).

Adapun dengan Virtual Reality, peserta didik dan tenaga pengajar terdorong untuk menuangkan kreativitas dan mempelajari kemampuan tambahan untuk merancang modul Virtual Reality. Melalui situs resmi Google Cardboard (yaitu salah satu teknologi Virtual Reality saat ini), disediakan suatu SDK khusus untuk perancangan modul Google Cardboard. SDK atau software development kit adalah tools khusus yang digunakan untuk mengembangkan aplikasi untuk paket software, framework, platform hardware atau sistem komputer tertentu. [19] SDK yang digunakan untuk merancang modul Google Cardboard adalah Cardboard SDK. Melalui SDK ini, pengguna dapat merancang modul imersif nya tersendiri dengan beberapa fitur seperti motion tracking, stereoscopic serta user interaction melalui 
tombol-tombol yang tersedia. [6] Melalui penjelasan pada situs resmi, Cardboard SDK cukup fleksibel dan versatile dalam pembuatan modul-modul. Melihat potensi dari suatu teknologi virtual reality, tim menerangkan beberapa modul yang dapat diterapkan dalam pembelajaran daring sebagai berikut.

\subsection{Model Kuis dan Ujian dengan Teknologi Virtual Reality}

Pada saat pembelajaran tidak dilakukan secara tatap muka atau secara online, bagian dari kegiatan belajar mengajar seperti ujian atau pengerjaan quiz masih tetap bisa dilaksanakan dengan memanfaatkan media online yang tersedia seperti ujian bisa dilakukan menggunakan google classroom dan sebagainya. Agar pembelajaran tidak terasa membosankan dan monoton, mengerjakan quiz online juga diharapkan dapat meningkatkan minat belajar bagi siswa serta mahasiswa.

Cara yang dapat dilakukan termasuk dengan teknologi Virtual Reality dan kuis serta ujian merupakan salah satu perangkat pembelajaran yang mudah untuk gamification in learning. Kuis dan ujian dapat menggunakan unsur game seperti pertandingan atau battle yang diselenggarakan secara kolektif dalam kelas melalui modul Virtual Reality.

\subsection{Modul Pembelajaran dengan Teknologi Virtual Reality}

Materi pembelajaran diberikan dan disesuaikan dengan tingkatan kelas dari setiap siswa. Materi pelajaran yang ditampilkan juga berasal dari buku-buku dan informasi yang sudah terbukti kebenarannya atau sudah valid. Penyampaian materi juga tentunya akan dikemas secara menarik dan unik agar para siswa lebih tertarik dan bersemangat untuk mengikuti pembelajaran.

Teknologi Virtual Reality akan membantu siswa-siswi untuk visualisasi materi dan pada akhirnya berperan pada memori dan student engagement. Modul pembelajaran haruslah mampu memenuhi kebutuhan untuk masing-masing mata pelajaran/mata kuliah. Beberapa modul di antaranya. Fisika, Matematika, dan cabang ilmu pengetahuan alam lainnya. Virtual Reality akan menggandakan aspek imersif dalam pembelajaran online, yaitu adanya visualisasi pada setiap contoh soal, pengayaan, penerapan dalam kehidupan nyata, dan pembahasan soal. Praktikum juga dapat diterapkan melalui Virtual Reality dimana modulnya dapat diatur sedemikian rupa untuk menunjang keberhasilan praktikum tersebut. Bahasa Inggris dan cabang ilmu pengetahuan bahasa lainnya. Virtual Reality menopang kebutuhan praktik nyata untuk melatih empat kemampuan umum berbahasa yaitu membaca, menulis, mendengar, dan berbicara. Dengan modul yang dapat dirancang sesuai kreativitas penggunanya, maka praktik pembelajaran dapat disesuaikan menjadi lebih bervariasi, unik, dan menyenangkan.

\subsection{Model Kelas Luring (luar jaringan/offline) dalam Kelas Daring (dalam jaringan/online)}

Istilah pembelajaran daring dan luring muncul sebagai salah satu bentuk pola pembelajaran di era teknologi informasi seperti sekarang ini. Pembelajaran daring dilakukan tanpa tatap muka, dapat dilaksanakan dimanapun dan kapanpun melalui platform yang tersedia.

Meskipun pembelajaran dilakukan secara daring peserta didik diharapkan dapat mengikutinya seperti pembelajaran tatap muka dengan cara peserta didik dan pengajar tetap melakukan komunikasi dengan baik, peserta didik juga harus aktif berdiskusi dengan pengajar dan teman lainnya saat pembelajaran daring berlangsung. Jika dalam suatu kelas dirasakan bahwa kondisi kelas Luring akan lebih kondusif, maka Virtual Reality dapat dipertimbangkan sebagai pilihan untuk meniru suasana kelas Luring dalam pembelajaran daring.

\subsection{Virtual Reality sebagai Media Presentasi}

Menurut hasil penelitian dari Ramdhan Dwi Ratriana, video pembelajaran berbasis VR memberikan dampak positif kepada siswa, siswa dengan mudah memahami materi yang ditayangkan, motivasi siswa terhadap kegiatan pembelajaran juga meningkat. Walaupun motivasi belajar setiap siswa berbeda tentang pembelajaran, hal ini berdasarkan kepada kecepatan respon siswa [20].

Maka untuk memaksimalkan penggunaan Virtual Reality, presentasi dalam kelas dan sebagai pelengkap tugas-tugas dapat menggunakan Virtual Reality. Dengan fleksibilitas yang dimiliki Virtual Reality, suasana presentasi dapat digandakan.

\section{KESIMPULAN}

Berdasarkan penelitian yang sudah dilakukan, berikut kesimpulan yang diperoleh.

1. Penggunaan VR pada pembelajaran daring akan sangat berguna dan membantu para pendidik dan peserta didik karena metode pembelajarannya yang berbeda dan unik. Dengan Virtual Reality, 
siswa-siswi dan tenaga pengajar terdorong untuk menuangkan kreativitas dan mempelajari kemampuan tambahan untuk merancang modul Virtual Reality. Melalui situs resmi Google Cardboard, disediakan suatu SDK khusus untuk perancangan modul Google Cardboard. SDK atau software development kit adalah tools khusus yang digunakan untuk mengembangkan aplikasi untuk paket software, framework, platform hardware atau sistem komputer tertentu. Penyampaian materi juga tentunya akan dikemas secara menarik dan unik agar para siswa lebih tertarik dan bersemangat untuk mengikuti pembelajaran.

2. Teknologi Virtual Reality akan membantu siswa-siswi untuk visualisasi materi dan pada akhirnya berperan pada memori dan student engagement. Modul pembelajaran haruslah mampu memenuhi kebutuhan untuk masing-masing mata pelajaran/mata kuliah. Praktikum juga dapat diterapkan melalui Virtual Reality dimana modulnya dapat diatur sedemikian rupa untuk menunjang keberhasilan praktikum tersebut.

3. Model pembelajaran dengan Virtual Reality dan gamification in learning memiliki beberapa modul penerapan yaitu: model kuis dan ujian dengan penerapan Virtual Reality, Modul pembelajaran dengan Teknologi Virtual Reality, meniru suasana kelas luring dalam kelas daring, dan Virtual Reality sebagai media presentasi.

4. Virtual Reality menopang kebutuhan praktik nyata untuk mata kuliah/mata pelajaran yang membutuhkannya.

\section{DAFTAR PUSTAKA}

[1] D. Putri Sundoro and S. Chendra Wibawa, "PENGEMBANGAN MEDIA PEMBELAJARAN VIDEO INTERAKTIF BERBASIS VIRTUAL REALITY (VR) PADA MATA PELAJARAN KOMPOSISI FOTO DIGITAL DI SMK KARTIKA 2 SURABAYA," Jul. 2019. Accessed: Dec. 17, 2020. [Online]. Available: https://jurnalmahasiswa3.unesa.ac.id/index.php/itedu/article/view/29996.

[2] I. Anugraheni, "Meta Analisis Model Pembelajaran Problem Based Learning dalam Meningkatkan Keterampilan Berpikir Kritis di Sekolah Dasar [A Meta-analysis of Problem-Based Learning Models in Increasing Critical Thinking Skills in Elementary Schools]," Polyglot J. Ilm., vol. 14, no. 1, p. 9, Jan. 2018, doi: 10.19166/pji.v14i1.789.

[3] C. J. Fluke and D. G. Barnes, "The Ultimate Display," 2016, [Online]. Available: http://arxiv.org/abs/1601.03459.

[4] C. Anthes, R. J. García-Hernández, M. Wiedemann, and D. Kranzlmüller, "State of the art of virtual reality technology," IEEE Aerosp. Conf. Proc., vol. 2016-June, no. March, 2016, doi: 10.1109/AERO.2016.7500674.

[5] "Google Cardboard - Google VR." https://arvr.google.com/cardboard/ (accessed Dec. 17, 2020).

[7] A. Jayul, E. Irwanto, P. Pendidikan, J. Kesehatan, and D. Rekreasi, "Model Pembelajaran Daring Sebagai Alternatif Proses Kegiatan Belajar Pendidikan Jasmani di Tengah Pandemi Covid-19," J. Pendidik. Kesehat. Rekreasi, vol. 6, no. 2, pp. 190 - 199-190 - 199, Jun. 2020, doi: 10.5281/zenodo.3892262.

[8] A. Rizkiyah, "PENERAPAN BLENDED LEARNING UNTUK MENINGKATKAN HASIL BELAJAR SISWA PADA MATA PELAJARAN ILMU BANGUNAN DI KELAS X TGB SMK NEGERI 7 SURABAYA," Jan. 2015. Accessed: Dec. 17, 2020. [Online]. Available: https://jurnalmahasiswa.unesa.ac.id/index.php/jurnal-kajian-ptb/article/view/10264.

[9] Y. Fitriyani, I. Fauzi, and M. Z. Sari, "Motivasi Belajar Mahasiswa Pada Pembelajaran Daring Selama Pandemik Covid-19," J. Kependidikan J. Has. Penelit. dan Kaji. Kepustakaan di Bid. Pendidikan, Pengajaran dan Pembelajaran, vol. 6, no. 2, p. 165, Jul. 2020, doi: 10.33394/jk.v6i2.2654.

[10] Y. Putri Utami and D. Alan Dheri Cahyono, "MATEMATIKA PADA PROSES PEMBELAJARAN DARING," Jun. 2020. Accessed: Dec. 17, 2020. [Online]. Available: http://jim.teknokrat.ac.id/index.php/pendidikanmatematika/article/view/252.

[11] A. Sadikin and A. Hamidah, "Pembelajaran Daring di Tengah Wabah Covid-19," BIODIK, vol. 6, no. 2, pp. 109-119, Jun. 2020, doi: 10.22437/bio.v6i2.9759.

[12] J. Kajian dan Riset Dalam Teknologi Pembelajaran and S. Ningsih, "PERSEPSI MAHASISWA TERHADAP PEMBELAJARAN DARING PADA MASA PANDEMI COVID-19 Article History," JINOTEP, vol. 7, no. 2, pp. 124-132, Oct. 2020, doi: 10.17977/um031v7i22020p124.

[13] U. Sa and J. Ariati, "HUBUNGAN ANTARA STUDENT ENGAGEMENT (KETERLIBATAN 
SISWA) DENGAN PRESTASI AKADEMIK MATA PELAJARAN MATEMATIKA PADA SISWA KELAS XI SMA NEGERI 9 SEMARANG," Jun. 2018. Accessed: Dec. 17, 2020. [Online]. Available: https://ejournal3.undip.ac.id/index.php/empati/article/view/20148.

[14] M. Sailer and L. Homner, "The Gamification of Learning: a Meta-analysis," Educ. Psychol. Rev., vol. 32, no. 1, pp. 77-112, 2020, doi: 10.1007/s10648-019-09498-w.

[15] A. K. Adisusilo, "Perancangan Media Pembelajaran Tematik Sekolah Dasar Berbasis Serious Game," vol. 10, no. 3, pp. 123-132, 2020.

[16] M. Sholihah, S. Utaya, and S. Susilo, "Pengaruh Model Experiential Learning Terhadap Kemampuan Berpikir Siswa Sma," J. Pendidik. - Teor. Penelitian, dan Pengemb., vol. 1, no. 11, pp. 2096-2100, 2016, doi: 10.17977/jp.v1i11.7869.

[17] H. Jusuf, "Penggunaan Gamifikasi dalam Proses Pembelajaran," Asosiasi Pendidikan Tinggi Ilmu Komputer Indonesia, 2016.

[18] M. Sailer, J. U. Hense, S. K. Mayr, and H. Mandl, "How gamification motivates: An experimental study of the effects of specific game design elements on psychological need satisfaction," Comput. Human Behav., vol. 69, pp. 371-380, 2017, doi: 10.1016/j.chb.2016.12.033.

[19] "CCNA Data Center DCICT 640-916 Official Cert Guide - Navaid Shamsee, David Klebanov, Hesham Fayed, Ahmed Afrose, Ozden Karakok - Google Buku." https://books.google.co.id/books?id=0GkBgAAQBAJ\&pg=PA934\&redir_esc=y\#v=onepage \&q\&f=false (accessed Dec. 17, 2020).

[20] R. D. Ratriana, "Pengembangan Video Pembelajaran Berbasis Virtual Reality Di Sekolah Dasar Islam Multiplus Ar Rahiim," pp. 1-14, 2017. 